\title{
Audit of outpatients: entering the loop
}

\author{
Iain K Crombie, Huw T O Davies
}

\section{Abstract}

Objective-To develop and test a method for routine data collection to observe current practice in outpatient pain clinics.

Design-Prospective questionnaire survey completed by consultants on each patient seen during October 1989 to May 1990.

Setting-Outpatient pain clinics of five teaching and five district general hospitals in Scotland and northern England.

Main outcome measures-Number of new referrals and their source, and characteristics of pain at presentation.

Results -4354 forms were completed by 21 consultants over 29 weeks, corresponding to 2241 patients, of whom 981 were new referrals. The proportion of consultations at which new referrals were seen varied among the 10 clinics from $15 \%$ to $34 \%$. The difference could not be accounted for by type of hospital. Sources of new referrals varied widely between the clinics (for example, range $22 \%$ to $78 \%$ for general practitioner referrals), as did new referrals by the type of pain (range $10.8 \%$ to $55 \cdot 2 \%$ for low back pain, $10 \cdot 5 \%$ to $32 \cdot 5 \%$ for pain associated with surgery). However, these differences in types of patients seen could not be accounted for by variations in referral patterns among clinics. Problems identified in performing an audit of outpatients included the difficulty of obtaining firm diagnoses, the need for a method to link successive patient contacts, and the complexity of the presenting problem in many patients.

Conclusions - It is possible to collect data for audit routinely in outpatient clinics. Observation of current practice in the clinics suggested possible unmet need or inappropriate management, which may require changes in practice.

\section{Introduction}

Outpatient services are a major component of health care, with a total of nearly 38 million patient attendances in 1986 in England and Wales. ${ }^{1}$ The contribution which audit could make to these services is suggested by the wide variations in outpatient activity among geographical regions ${ }^{2}$ and by concern about the appropriateness of some attendances.

One of the problems facing audit of outpatients is the paucity of routinely collected data: the Körner minimum data set was recently described as "virtually useless" for assessing outpatient services. ${ }^{+}$The Royal College of Physicians has also recognised the difficulties of collecting suitable data for audit of outpatients and the need to explore new methods. Furthermore, it has been suggested that the effort of setting up an audit of outpatient activity does not justify the return. ${ }^{\circ}$

Under the auspices of the North British Pain Association we established a survey of patients seen in
10 outpatient pain clinics. Its aims were to describe the sources of referral, the problems of these patients, and their management. This required the development of a method of data capture in busy outpatient clinics and provided the opportunity of identifying problems facing the first stage of the audit cycle-that is, observing current practice.

\section{Methods}

We conducted the survey over 29 weeks from October 1989 to May 1990 in outpatient pain clinics in five teaching hospitals and five district general hospitals in Scotland and the north of England, which were chosen because of good personal contacts with the clinic consultants. A local coordinator was identified in each, who distributed forms to the clinic doctors and returned completed forms to us for processing and analysis. We maintained regular contact with the clinicians, including feedback of data, to encourage compliance.

To increase the accuracy of the clinical data the forms were completed by the doctors during the consultation and hence had to be short and easy to complete. The form was developed over several pilot studies, in which the clinic consultants were involved, so that the final version was acceptable and workable. Basic demographic details, source of referral, and a description of the presenting complaint (nature, severity, and likely cause) were collected (appendix). Repeat visits by the same patient were identified by linking forms through surname, initial of first name, date of birth, and, when available, the clinic's patient reference number.

As this study was descriptive with no prior hypotheses to be tested we avoided formal testing of significance. However, to help interpret differences in proportions it should be noted that with a sample size of 100 the maximum possible value of the $95 \%$ confidence interval would be $\pm 5 \%$, and with a sample size of 50 it would be $\pm 14 \%$. Furthermore, all global

TABLE I-Consultations, patients, and new referrals by clinic

\begin{tabular}{|c|c|c|c|c|}
\hline Clinic No & $\begin{array}{c}\text { Consultations } \\
(\mathrm{No})\end{array}$ & $\begin{array}{l}\text { Patients } \\
(\text { No }(\%))\end{array}$ & $\begin{array}{c}\text { Total new } \\
\text { referrals } \\
\left(\text { No }\left(\%^{\star}\right)\right)\end{array}$ & $\begin{array}{l}\text { General } \\
\text { practitioner } \\
\text { referrals } \\
(\text { No }(\% \dagger))\end{array}$ \\
\hline \multicolumn{5}{|c|}{ Teaching hospitals } \\
\hline 1 & 361 & $166(46)$ & $80(22)$ & $40(50)$ \\
\hline 2 & 666 & $293(44)$ & $100(15)$ & $43(43)$ \\
\hline 3 & 846 & $479(57)$ & $204(24)$ & $45(22)$ \\
\hline 4 & 375 & $235(63)$ & $127(34)$ & $64(50)$ \\
\hline 5 & 725 & $415(57)$ & $159(22)$ & $55(35)$ \\
\hline \multicolumn{5}{|c|}{ District general hospitals } \\
\hline 6 & 176 & $69(39)$ & $37(21)$ & $16(43)$ \\
\hline 7 & 490 & $204(42)$ & $87(18)$ & $43(49)$ \\
\hline 8 & 147 & $97(66)$ & $50(34)$ & $39(78)$ \\
\hline 9 & 249 & $127(51)$ & $61(25)$ & $30(49)$ \\
\hline 10 & 319 & $156(49)$ & $76(24)$ & $58(76)$ \\
\hline Total & 4354 & $2241(52)$ & $981(23)$ & $433(44)$ \\
\hline
\end{tabular}

Correspondence to:

Dr Crombie.

BMF 1991;302:1437-9 
example, neurology contributed no patients in six of

\begin{tabular}{|c|c|c|c|c|}
\hline \multirow[b]{2}{*}{ Clinic No } & \multicolumn{2}{|c|}{ Low back pain ${ }^{\star}$} & \multicolumn{2}{|c|}{ Surgery related pain ${ }^{\star}$} \\
\hline & $\begin{array}{c}\%(\text { No) } \\
\text { observed }\end{array}$ & $\begin{array}{c}\%(\mathrm{No}) \\
\text { expected } \dagger\end{array}$ & $\begin{array}{c}\%(\mathrm{No}) \\
\text { observed }\end{array}$ & $\begin{array}{l}\%(\mathrm{No}) \\
\text { expected } \dagger\end{array}$ \\
\hline \multicolumn{5}{|c|}{ Teaching hospitals } \\
\hline 1 & $32 \cdot 5(26)$ & $31 \cdot 5(25 \cdot 2)$ & $32 \cdot 5(26)$ & $22 \cdot 6(18 \cdot 1)$ \\
\hline 2 & $17 \cdot 0(17)$ & $28 \cdot 4(28 \cdot 4)$ & $25 \cdot 0(25)$ & $21 \cdot 8(21 \cdot 8)$ \\
\hline 3 & $30 \cdot 9(63)$ & $36 \cdot 6(74 \cdot 6)$ & $18 \cdot 1(37)$ & $23 \cdot 6(48 \cdot 1)$ \\
\hline 4 & $48 \cdot 0(61)$ & $42 \cdot 3(53 \cdot 7)$ & $24 \cdot 4(31)$ & $19 \cdot 6(24 \cdot 9)$ \\
\hline 5 & $32 \cdot 1(51)$ & $34 \cdot 1(54 \cdot 2)$ & $25 \cdot 2(40)$ & $20 \cdot 8(33 \cdot 0)$ \\
\hline \multicolumn{5}{|c|}{ District general hospitals } \\
\hline 6 & $10 \cdot 8(4)$ & $28 \cdot 6(10 \cdot 6)$ & $13 \cdot 5(5)$ & $22 \cdot 2(8 \cdot 2)$ \\
\hline 7 & $55 \cdot 2(48)$ & $41 \cdot 4(36 \cdot 0)$ & $20 \cdot 7(18)$ & $17 \cdot 4(15 \cdot 1)$ \\
\hline 8 & $38 \cdot 0(19)$ & $35 \cdot 8(17 \cdot 9)$ & $12 \cdot 0(6)$ & $17 \cdot 0(8 \cdot 5)$ \\
\hline 9 & $50 \cdot 8(31)$ & $40 \cdot 7(24 \cdot 8)$ & $9 \cdot 8(6)$ & $19 \cdot 7(12 \cdot 0)$ \\
\hline 10 & $44 \cdot 7(34)$ & $37 \cdot 6(28 \cdot 6)$ & $10 \cdot 5(8)$ & $16 \cdot 3(12 \cdot 4)$ \\
\hline Total & $36 \cdot 1(354)$ & $36 \cdot 1(354)$ & $20 \cdot 6(202)$ & $20 \cdot 6(202)$ \\
\hline
\end{tabular}

^Either as sole problem or in combination.

tCalculated as described in methods section.

tests of differences among clinics shown in tables I and II, using the $\chi^{2}$ test, were significant at $\mathbf{p}<0 \cdot 01$.

The expected number of referrals of a particular type of patient (for example, with low back pain) was calculated for clinic 1 as follows: the proportion of these patients referred from a particular source, aggregated over all clinics, was calculated. This proportion was multiplied by the number of patients referred to clinic 1 from that source. Repeating this calculation for each source of referral and then summing the values yields the number of referrals for low back pain expected at clinic 1, given its referral pattern. The same method was used for each type of patient at each of the clinics in turn.

\section{Results}

The number of forms returned by each clinic during the 29 weeks ranged from 147 to 846 (table I). Over this period the quality of completions was high: for almost all fields the proportion of missing values was less than $3 \%$. Many patients attended the clinics more than once during the study period, and the number of patients seen varied between 69 and 479. The differences among the clinics in the balance between repeat versus new consultations was most clearly evident by expressing the number of new referrals as a proportion of the total number of consultations. Table I shows that the rate of new consultations varied between $15 \%$ and $34 \%$ and could not be explained by type of hospital (teaching or district general). More detailed analysis for the centres with widely divergent values in table I showed that during the same 29 weeks clinic 4 saw only one third $(34 \cdot 7 \%)$ of patients more than once whereas clinic 2 saw almost two thirds $(65 \cdot 5 \%)$ more than once. The difference in the proportions of consultations spent seeing repeat patients was not due to differences in the types of patients seen: similar results were obtained when the results were analysed by selected patient groups (for example, among patients with low back pain the proportions seen more than once at the two clinics were $43.0 \%$ and $78.6 \%$ and in those with pain associated with surgery they were $40.5 \%$ and $76 \cdot 4 \%)$

There was considerable variation among the clinics in the sources of referral of patients. The proportion of new patients referred by general practitioners ranged from less than a quarter to over three quarters (table I). The proportions of referral of new patients from orthopaedic surgery (data not shown) varied fourfold among clinics and this difference was preserved when account was taken of the variation in the numbers of general practitioner referrals (by calculating the percentages as a proportion of the number of nongeneral practitioner referrals). Wide variation was also seen in referrals from the other specialties-for the 10 centres and neurosurgery none in three clinics, and this occurred in both teaching and district general hospitals.

As expected from the differences in sources of referral large differences also existed among clinics in the types of patients seen, both in terms of the location of their pain and its probable cause. For example, the proportion of new referrals of patients with low back pain ranged from $10 \cdot 8 \%$ to $55 \cdot 2 \%$ and the proportion in whom surgery was implicated as a cause ranged from $9 \cdot 8 \%$ to $32 \cdot 5 \%$ (table II). The extent to which these differences may be explained by variations in referral patterns was investigated by calculating the number of referrals of a particular type which would be expected in each clinic, given its referral pattern (see methods). Table II shows that differences in the proportions of referrals of patients with low back pain would indeed be expected (range $28 \cdot 4 \%$ to $42 \cdot 3 \%$ ). However, the clinics with high expected referral rates had even higher observed rates whereas those with low expected rates had lower observed rates. In contrast, despite varied referral patterns differences among clinics would not be expected for patients in whom surgery was a cause of their pain: each clinic would expect about a fifth of its patients to have pain associated with surgery (table II).

One feature of the patients seen was the complexity of their problems with pain-for example, one third had pain affecting two or more major body sites and a fifth had two or more diagnoses directly related to their pain. Diagnosis proved to be a problem in the survey, and although some specific diagnoses were recorded, others were essentially a restatement of symptoms, location, or cause (table III). This reflects the real difficulty of diagnosis in many patients with pain, a point highlighted by the common use of colloquial "diagnoses." A further problem was the diversity of conditions: over 400 distinct "diagnoses" were recorded for the 2241 patients seen.

The study provided data on the types of patients seen at pain clinics. Low back pain was the most common location of pain, being reported by 354 (36\%) of new patients; the other important sites were buttock or leg $(301,31 \%)$, thorax $(192,20 \%)$, shoulder or arm $(172,18 \%)$, and neck $(127,13 \%)$. The important aetiological factors were degenerative disease $(36 \%)$, surgery $(21 \%)$, and trauma (17\%). The problem with pain was commonly long standing: $60 \%$ of patients reported having had their pain for over two years.

\section{Discussion}

The main finding of this study is that the first stage of the audit cycle, observing current practice, ${ }^{7}$ may be achieved for outpatients. Further, comparisons among clinics raise important questions about both the provision and the delivery of care to patients with chronic pain. These findings indicate that although, as Ellis pointed out, audit of outpatients may be difficult, there is a clear need for it. One aspect meriting further study is the differences in the number of patients seen at each clinic: although consultation rates could not be calculated because the catchment populations were not known, the areas served by clinics 1 and 3 are of similar size and have no other pain clinics. Geographical differences in morbidity alone seem unlikely to account for the wide differences observed among clinics.

The diversity observed in the sources of referral at the 10 clinics is also important. Although one clinic (centre 3) does not encourage direct referrals from general practitioners, this still leaves much of the difference unexplained. Furthermore, there are no obvious restraints placed on referrals from other 
hospital specialties, but again considerable variation was seen. Differences among the clinics were also found in the types of patients seen, and standardisation for referral pattern accounted for only part of these differences. Patients not seen at these clinics are probably being managed elsewhere, although this is not certain. Alternatively, particular clinics may gain a reputation for treating certain categories of patients and attract them from all sources. Whatever the explanation, the differences among the clinics imply the existence of either unmet need or inappropriate management. Standard textbooks on managing pain recommend that patients with chronic pain be treated at specialist pain clinics, where consultants have more experience of effective but specialised techniques. ${ }^{8 / 10}$

A further area for investigation is the variation in approaches to patient management. Clinics differ appreciably in the way in which repeat appointments are arranged, even for patients who have the same type of problem. This suggests that some clinics may offer too frequent or too many repeat appointments and in

\section{Appendix}

\section{Basic patient details}

Clinic date:

Sex: Male Female

$\square$ Date of birth:

[] Patient number:

\section{Place label here}

Patient's home:

Source of referral:

$\begin{array}{lll}\text { Local } & \square & \text { Distant } \\ \text { GP } & \square & \text { Neurosurgery } \\ \text { Physician } & \square & \text { Neurology } \\ \text { Orthopaedics } & \square & \text { General surgery }\end{array}$

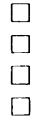

Psychiatry/psychology Oncology/radiotherapy Other Specify: consequence be able to see fewer new patients. Alternatively, other clinics may see patients too infrequently to give appropriate care.

The study identified several problems facing audit of outpatients. The first concerns the difference between patients and consultations. Audit of inpatients typically deals with a single patient episode from admission to some convenient point such as discharge ${ }^{11}$ or 30 days from surgery. ${ }^{12}$ Outpatients, however, make repeated visits, often over several years, so the distinction has to be made between consultations, patients, and new referrals. The number of consultations gives an estimate of workload, that of patients estimates the amount of illness being seen, and that of new referrals gives information on patient throughput. Thus surveys in outpatients require collection of sufficient data to enable the unique identification of patients and a method of analysis which permits matching of consultations for the same patient. A second problem is the difficulty with firm diagnoses. The problem is compounded because reporting is done by many different clinicians, who give differing amounts of detail and may use alternative terms for the same conditions. This impedes the use of computerised audit systems as commercial software packages use coding systems for diagnosis, such as the Read classification or ICD (ninth revision), which require precise diagnoses. ${ }^{13}$ The unsuitability of these coding systems when diagnosis is uncertain was recently pointed out. ${ }^{14}$ The solution adopted for this study was to record selected symptom characteristics (site, intensity, and time course of pain) and the possible aetiology as well as the "diagnosis." Because many patients had more than one problem with pain, provision had also to be made for multiple recording of patient characteristics.

In summary, this study showed that despite many problems it is possible to observe current practice in outpatients and that doing so identified important areas in which to effect change.

This study was funded by the Ian Mactaggart Trust; IKC was supported by the Scottish Home and Health Department. We thank the North British Pain Association for their cooperation, and, in particular, the clinicians and staff in the 10 participating pain clinics.

1 Department of Health. Health and personal social services statistics for England and Wales for 1988. London: $\mathrm{DoH}, 1989$.

Fowkes FGR, McPake BI. Regional variation in outpatient activity in England and Wales. Community Med 1986;8:286-91

3 Shaw CD. The problem of out-patient visits. Health Trends 1981;13:107-8.

4 Scott DL, Haslock I. Measuring performance in clinical rheumatology. Ann Rheum Dis 1990;49:3-5.

Royal College of Physicians. Medical audit. A first report. What, why and how? Lon: 1989.

London: 1989.
Ellis BW. How to set up an audit. $B M 7$ 1989;298:1635-7.

6 Ellis BW. How to set up an audit. BMF 1989;298:1635-7.

Fowkes F GR. Medical andic cycle. Med Educ 1982,16:228-38. Bonica JJ. General considerations of chronic pain. In: Bonica JJ, Loeser JD,
Chapman CR, Fordyce WE, eds. The management of pain. 2nd ed. Vol I. Philadelphia: Lea and Febiger, 1990:180-96.

9 Swerdiow $M$. The pain relief clinic. In: Anderson S, Bond $M$, Mehta $M$, Swerdlow M, eds. Chronic non-cancer pain. Lancaster, England: MTP Press, 1987:189-96.

10 Bond MR. Pain: its nature, analysis and treatment. 2nd ed. Edinburgh: Churchill Livingstone, 1984:203.

11 Ellis BW, Michie HR, Esufali ST, Pyper RJD, Dudley HAF. Development of a microcomputer-based system for surgical audit and patient administration: a review. $7 R$ Soc Med 1987;80:157-61.

12 Gruer R, Gordon DS, Gunn AA, Ruckley CV. Audit of surgical audit. Lancet 1986;i:23-6.

13 Tyndal R, Kennedy S, Naylop S, et al. Computers in medical audit. London: Royal Society of Medicine, 1990.

14 Jones RG, Page KB. Read clinical classification. BMJ 1990;300:1467. 